\title{
El tratamiento fotoperiodístico en las portadas de los diarios digitales. Propuesta y aplicación de un modelo de análisis
}

Photojournalistic treatment on the front pages of digital newspapers.

\section{Proposal and application of an analysis model}

Joaquín López del Ramo. Universidad Rey Juan Carlos

Recibido: 19-II-2010 - Aceptado: 30-IV-2010

Resumen:

Evaluación de los usos fotoperiodísticos en los diarios digitales El Mundo, La Vanguardia, Sur y La Voz de Galicia, durante el mes de enero de 2010. Se emplea un modelo de análisis original para extraer valores cuantitativos y cualitativos. El objetivo es contrastar anteriores estudios y descubrir nuevas tendencias. Los resultados revelan que se publican numerosas fotos, pero casi siempre son decorativas; tienen pequeño tamaño, encuadres cortos y están poco jerarquizadas. Las conclusiones son: a) Las fotografías tienen en general escaso valor informativo. b) Se produce un empobrecimiento expresivo, masificación e irrelevancia. c) Los ciberdiarios emplean fórmulas fotográficas semejantes.

Palabras clave:

Fotoperiodismo, ciberperiodismo, fotografía, maquetación, diseño periodístico, ilustración, galerías.

Abstract:

Evaluation of the photojournalistic uses in the digital newspapers El Mundo, La Vanguardia, Sur and La Voz de Galicia, during January, 2010. We use an original analysis model to extract quantitative and qualitative values. The aim is to contrast previous studies and to discover new trends. The results reveal that numerous photos are published, but almost always they are decorative; they have small size and close-up framing and they are poorly ranked. The conclusions are: a) Photographs have, in general, limited informative value. $b$ ) The analysis reveals a situation of expressive impoverishment, mass-production and immateriality. c) The web newspapers use similar photographic methods.

Key words:

Photojournalism, Cyberjournalism, Photography, Layout, Journalistic Design, Illustration, Galleries 


\section{Introducción}

La aparición y desarrollo de los medios on-line de prensa escrita ha dado lugar a profundos cambios en la concepción y el diseño de la noticia respecto a las fórmulas preexistentes en el periodismo impreso. Existe una notable coincidencia en señalar a la fotografía periodística como uno de los elementos más afectados en este proceso. Con más propiedad, cabría hablar quizás de una auténtica convulsión, que ha trastocado de forma sustancial el papel de la fotografía en los ciberdiarios en relación con las prácticas clásicas, hasta el punto que ya muchos profesionales y estudiosos dudan sobre su propia vigencia como elemento portador de un mensaje comunicativo relevante, y no digamos ya sobre la posibilidad de ser el centro o leiv motiv de la noticia.

Algunos investigadores han realizado en los últimos años interesantes aportaciones de base empírica, aún escasas numéricamente, a través de las cuales es posible componer un cuadro descriptivo sobre la situación actual del fotoperiodismo en dichos medios. Se han identificado sus fórmulas de tratamiento, su evolución, sus tendencias y muchos de los efectos comunicativos que de todo ello se derivan, tanto en sí mismos como en comparación con los periódicos en soporte papel.

Parece evidente que el nuevo escenario tecnológico de la digitalización ofrece a la fotografía periodística ventajosos y anteriormente insospechados cauces de enriquecimiento. El desarrollo de las galerías en sus distintas variantes, incluidas las de tipo participativo, es quizás uno de los aspectos emergentes, como revela un informe publicado por The Bivings Group (Johnson, 2008) sobre el uso de Internet en los principales diarios de EEUU, que cifra en el 58\% los periódicos que permiten la inclusión de fotos de los lectores.

Se habla a menudo del nuevo espacio generado por Internet, en el cual se amplían, al menos potencialmente, las posibilidades de utilización de la fotografía periodística (Munhoz, 2001: 13), "disponibilizándola de manera creativa y dinámica, proporcionando transformaciones significativas en la narrativa del hecho periodístico". No obstante, las pocas investigaciones empíricas realizadas hasta ahora insisten en subrayar que el tratamiento de la fotografía en los diarios on-line, por encima de su crecimiento cuantitativo y de sus potencialidades teóricas, adolece en la práctica de más aspectos negativos que positivos.

A modo de síntesis sobre el estado de la cuestión, y en el sentido de aportar una mayor clarificación sobre el mismo, pueden distinguirse tres grupos de categorías:

a) Problemas estructurales: entendiendo por tales los que afectan de un modo genérico a la fotografía y tienen su origen en limitaciones tecnológicas o rutinas profesionales de los nuevos medios: 
- $\quad$ El tamaño reducido del monitor respecto al periódico tradicional (Caminos, Murillo y Armentia, 2006a: 12) es un grave inconveniente. Aunque esto podrá corregirse previsiblemente a medio plazo con el aumento de formato de estos dispositivos, en el momento presente aún constituye una cortapisa notable.

- Imágenes con vigencia temporal breve, derivada de la misma naturaleza dinámica de la web y su capacidad de actualización casi automática, lo que ha impuesto como rutina mecánica y pautada el refresco de contenidos con cadencias fijas en las ediciones digitales de los periódicos.

b) Problemas de puesta en página: los propios de la maquetación:

- Masificación iconográfica: el aspecto sobresaturado es algo muy frecuente en las portadas de los diarios digitales. La atención se reparte entre fotos de diferentes tamaños, formas, ubicaciones, capturas de vídeos, fotomontajes, gráficos, iconos, etc. que muchas veces, además, aparecen confusamente mezclados unos con otros. Esta disfunción contraviene una de las normas básicas del diseño de interfaz, ya enunciada hace tiempo (Nielsen, 2000: 134) y reafirmada con posterioridad cuando se habla de la conveniencia de "minimizar el ruido" evitando las páginas con aspecto abrumador, donde todo llama la atención (Krug, 2006: 38).

- $\quad$ Exceso de frames suplantadores, es decir, fotogramas de vídeos que actúan muchas veces como sucedáneos de las fotografías. Este aspecto ha sido certeramente analizado en un reciente trabajo (Villa, 2008: 307), que remarca un hecho sustancial: "el frame es el resultado de rutinas productivas aceleradas, capaces de generar cada día contenidos más profusamente ilustrados pero escasa diversidad y calidad de imágenes”.

- Maquetación rígida: el diseño de las páginas web suele tener una notable rigidez, que viene determinada por las plantillas del gestor de contenidos con las que se trabaja o el uso que se hace de las mismas. Salvo excepciones muy puntuales, las fotos se constriñen al marco fijo preestablecido, especialmente respecto al ancho de las mismas, pues van insertas en paneles verticales a manera de módulos de ancho fijo y aparentemente infranqueable.

- $\quad$ Fotos en tamaño muy reducido: práctica rutinaria y muy extendida, que llevada al extremo dan a la fotografía un aspecto que se valora (Caminos, Murillo y Armentia, 2006b: 35) como "casi ridículo, y correspondería a lo que en el argot de las redacciones periodísticas se denominan cromos". Ello se une al escaso uso de la ampliación de la imagen, lo que da a muchas fotos un aspecto de miniatura irrelevante. 
Claro predominio de fotos en plano corto, lo que acarrea una gran pérdida de detalles generales, con la consiguiente descontextualización situacional o escenográfica dentro de la propia imagen.

- $\quad$ Sobreabundancia de retratos: "se puede constatar a través del estudio realizado que casi todos los periódicos utilizan la fotografía tipo retrato como en la mitad de sus ilustraciones” (Sánchez Vigil, Marcos y Villegas, 2007a: 218). Este rasgo abunda en la monotonía del discurso visual, además de suponer una característica en gran medida arcaizante, pues no debemos olvidar que el retrato, junto con el paisajismo, eran los géneros esenciales en los primeros tiempos de la fotografía en prensa, como herencia de la tradición pictórica.

- $\quad$ Alto porcentaje de fotografías no adecuadas al contenido de la información (máximo 50\%, mínimo 29\%), (Sánchez Vigil, Marcos y Villegas, 2007b: 214). Este recurso a las fotografías de relleno, carentes de significado claro, se produce en muchas ocasiones cuando "nos sentimos obligados incluir imágenes porque sabemos que el Web es un medio visual, y tenemos que usarlas para añadir un poco de picante a nuestras páginas" (Horton, 2006).

- Galerías genéricas, con fotos descontextualizadas, muchas veces seleccionadas con un criterio simplemente colorista o espectacular, o carentes de unidad temática, a modo de "cajón de sastre" (Caminos, Marín y Armentia, 2006c: 36). Estas fotos no ilustran ninguna información, y sólo llevan un pequeño texto para aclarar su significado, que a veces no basta para darles coherencia ni para lograr la comprensión íntegra del hecho noticioso al que aluden.

- $\quad$ Bajo nivel de identificación de autoría: preponderancia de las agencias en perjuicio de los fotógrafos del periódico.

c) Problemas de usabilidad: que atañen a la facilidad y claridad de uso por parte del lector digital, y que por su especificidad y novedad merecen ser objeto de un análisis independiente. La mayor parte se refieren a la inexistencia de normas evidentes respecto al funcionamiento de los enlaces establecidos en las fotografías, al hecho de que existan o no, a su discutible evidencia para el usuario y al resultado que ofrecen tras el clic.

De todo lo dicho podría deducirse que en muchos aspectos la praxis actual de los ciberdiarios altera las bases del fotoperiodismo clásico, recogidas en la definición de esta disciplina (Rodríguez Merchán, 1993: $114)^{1}$. Se diluyen o quedan en entredicho las funciones típicamente informativas del fotógrafo de prensa,

\footnotetext{
1 "La notificación de acontecimientos reales, interpretados visualmente por un fotógrafo y orientados por unos criterios de contingencia, mediatizados por varios procesos codificadores (fotográfico, informativo y de impresión fotomecánica) y que produce un mensaje visual que es interpretado por el receptor según su competencia icónica y su conocimiento del contexto".
} 
como mediador y codificador del mensaje visual. Las fotos quedarían relegadas a cumplir un papel secundario, una mera ilustración, como simple acompañamiento del texto.

Así pues, parece claro que se ha abierto una brecha entre la función e importancia de la fotografía periodística en los diarios impresos y en los digitales. Asumida esta hipótesis, las consecuencias comunicativas que de ello se derivan, por un lado, y la conveniencia de contar con un instrumento de análisis que permita examinar de una forma sistemática y clara el tratamiento de las fotos en los diarios on-line, son las principales motivaciones del presente trabajo, que persigue los siguientes objetivos:

- Analizar los cambios producidos en el tratamiento de la fotografía informativa en los medios de prensa on-line respecto a los de soporte papel, valorando los efectos comunicativos a los que han dado lugar.

- Crear un modelo de análisis de las fotografías publicadas en los periódicos on-line que integre variables hasta ahora dispersas e incorpore otras nuevas, adecuadas al objetivo expuesto con anterioridad.

- Utilizar dicho modelo como herramienta para obtener datos que permitan contrastar las tendencias registradas en anteriores estudios o aportar otras nuevas, tanto desde el punto de vista cuantitativo como cualitativo.

\section{Metodología}

Para la realización del estudio se ha procedido al diseño y creación de una matriz de análisis acorde al objeto, características y alcance de la investigación integrada por 23 indicadores. Para ello se han tomando como base los estudios anteriormente aludidos de Caminos Marcet, Marín Murillo y Armentia, los de Sánchez Vigil, Marcos Recio y Villegas y Villa.

La relación de indicadores y sus posibles valores se desglosan en la siguiente ficha:

\begin{tabular}{|c|c|c|}
\hline No $\quad$ Ref. & Variables & Valores \\
\hline \multicolumn{3}{|l|}{ Nivel: Página } \\
\hline 1 & Fotos por página & Número \\
\hline 2 & Frames por página & Número \\
\hline 3 & Fotos de llamada a noticias & Número \\
\hline 4 & Fotos de llamada a galerias & Número \\
\hline
\end{tabular}




\begin{tabular}{|c|c|c|}
\hline 5 & $\begin{array}{l}\text { Otras fotos referidas a contenidos } \\
\text { informativos }\end{array}$ & Número \\
\hline 6 & $\begin{array}{l}\text { Fotos genéricas: de Secciones o de } \\
\text { Identidades personales (avatares): }\end{array}$ & Número \\
\hline 7 & $\begin{array}{l}\text { Imágenes de carteles, fotogramas, } \\
\text { pantallazos o fotomontajes. }\end{array}$ & $\begin{array}{l}\text { O Sí } \\
\text { ○ No }\end{array}$ \\
\hline 8 & $\begin{array}{l}\text { Tamaño (ancho) menor al 25\% } \\
\text { de la mancha }\end{array}$ & $\begin{array}{l}\text { 1. Ninguna } \\
\text { 2. Menos del } 25 \% \\
\text { 3. Entre el } 25 \text { y el } 50 \% \\
\text { 4. Más del } 50 \% \\
\text { 5. Todas }\end{array}$ \\
\hline 9 & $\begin{array}{l}\text { Tamaño (ancho) entre el 25\% y } \\
\text { el 50\% de la mancha }\end{array}$ & $\begin{array}{l}\text { 1. Ninguna } \\
\text { 2. Menos del } 25 \% \\
\text { 3. Entre el } 25 \text { y el } 50 \% \\
\text { 4. Más del } 50 \% \\
\text { 5. Todas }\end{array}$ \\
\hline 10 & $\begin{array}{l}\text { Tamaño (ancho) mayor al 50\% } \\
\text { de la mancha }\end{array}$ & $\begin{array}{l}\text { 1. Ninguna } \\
\text { 2. Menos del } 25 \% \\
\text { 3. Entre el } 25 \text { y el } 50 \% \\
\text { 4. Más del } 50 \% \\
\text { 5. Todas }\end{array}$ \\
\hline 11 & Efecto cromos & $\begin{array}{l}\text { O Sí } \\
\text { O No } \\
\text { O Extremo }\end{array}$ \\
\hline 12 & $\begin{array}{l}\text { ¿Se permite la descarga } \\
\text { a tamaño ampliado? }\end{array}$ & $\begin{array}{l}\text { 1. Ninguna } \\
\text { 2. Menos del } 25 \% \\
\text { 3. Entre el } 25 \text { y el } 50 \% \\
\text { 4. Más del } 50 \% \\
\text { 5. Todas }\end{array}$ \\
\hline
\end{tabular}




\begin{tabular}{|c|c|c|}
\hline 13 & $\begin{array}{l}\text { Tamaños de fotos distintos se } \\
\text { emplean en la página }\end{array}$ & $\begin{array}{l}\text { 1. Uno } \\
\text { 2. Entre } 2 \text { y } 3 \\
\text { 3. Entre } 4 \text { y } 5 \\
\text { 4. Entre } 6 \text { y } 7 \\
\text { 5. Más de } 7\end{array}$ \\
\hline 14 & $\begin{array}{l}\text { ¿Se compone una foto mayor } \\
\text { que el resto? }\end{array}$ & $\begin{array}{l}\text { O Sí } \\
\text { O No }\end{array}$ \\
\hline 15 & Encuadre & $\begin{array}{l}\text { 1. General (\%): } \\
\text { 2. Medio (\%): } \\
\text { 3. Corto (\%): }\end{array}$ \\
\hline 16 & Retratos & \% sobre el total de fotos \\
\hline 17 & Valor informativo & Porcentaje \\
\hline 18 & ¿Tiene pie de foto? & $\begin{array}{l}\text { 1. Ninguna } \\
\text { 2. Menos del } 25 \% \\
\text { 3. Entre el } 25 \text { y el } 50 \% \\
\text { 4. Más del } 50 \% \\
\text { 5. Todas }\end{array}$ \\
\hline 19 & Identificación de la autoría o fuente & $\begin{array}{l}\text { 1. Ninguna } \\
\text { 2. Menos del } 25 \% \\
\text { 3. Entre el } 25 \text { y el } 50 \% \\
\text { 4. Más del } 50 \% \\
\text { 5. Todas }\end{array}$ \\
\hline 20 & Tipos de galerías & $\begin{array}{l}\text { 1. Genérica: Imágenes del Día } \\
\text { 2. Galerías de Sección } \\
\text { 3. Galerías de Acontecimiento } \\
\text { 4. Galerías de lectores }\end{array}$ \\
\hline
\end{tabular}

Como puede apreciarse, la mayor parte de los indicadores de la matriz informan sobre aspectos de tipo cuantitativo, en los que centra este análisis. Únicamente el indicador 17 (valor informativo) posee un sentido cualitativo, centrado en determinar el porcentaje de fotos que portan un valor noticioso, testimonial o interpretativo relevante a la información que aluden. 
En cuanto al procedimiento metodológico, se escogió una muestra compuesta por las primeras páginas de los siguientes diarios digitales: El Mundo, La Vanguardia, Sur de Málaga y La Voz de Galicia. La elección de dichas cabeceras se realizó teniendo en cuenta criterios que, dentro del alcance y límites del trabajo, le otorgara un grado de representatividad y coherencia adecuado. Así, se trata de periódicos editados en diferentes puntos de España, todos ellos líderes de audiencia en sus respectivos puntos de origen y otro, El Mundo, a escala nacional, y pertenecientes a grupos editoriales también distintos.

Las consultas se han llevado a cabo en las mismas franjas horarias para todos los periódicos, entre las 15’00 y las 18'30 horas, correspondientes a las ediciones de tarde. En todos los casos, a la hora de la consulta ya habían tenido lugar varias actualizaciones, lo que en algunos momentos también se ha producido parcialmente durante la propia realización del trabajo. Se escogieron únicamente días laborables, completando todos los de la semana, en concreto los siguientes: del martes 19 al viernes 22 de enero y el lunes 25 de enero de 2010. Como quedó consignado, sólo se ha procedido al análisis de las primeras páginas, objeto concreto de este trabajo, si bien el modelo está concebido para ser aplicado también a páginas interiores.

En relación a los criterios generales del análisis, es necesario clarificar que se excluyeron de la consideración de fotografías, y por tanto no se computan ni examinan, los siguientes elementos iconográficos: los fotomontajes con texto y fotos, iconos con base fotográfica, fotos-miniatura ubicadas en las barras de desplazamiento de galerías y fotos de carteles, fotogramas, "pantallazos" o fotomontajes.

Las fotos genéricas (indicador 8 de la matriz), si se computan en sus dos categorías: cabeceras fotográficas de llamada a secciones y fotos de identificación personal (avatares), pero no se analizan sus características por carecer de valor noticioso, pues cumplen una función meramente decorativa. Las fotos que sí se computan y analizan son las de tipo informativo que a su vez se desglosan en varios subtipos, según su función, distinguiéndose en fotos de llamada a noticias o sumarios, fotos de llamada a galerías y otras con vínculo a contenidos informativos.

Partiendo de los anteriores postulados, el número total de fotos computadas ascendió a 496, de las cuales pertenecían a la categoría de fotos informativas un total de 278. Dado que únicamente se analizan las características de fotos informativas, los porcentajes de los indicadores se realizan tomando como referencia la cifra de 278.

Los datos obtenidos fueron volcados sobre una base de datos de Access integrada en Excel, cuyo formato de registro se corresponde con la matriz de análisis. A partir de los mismos, se lleva a cabo en primer término una exploración univariada, que permite obtener las frecuencias totales generales de los indicadores 
individuales, y en segundo término un análisis bivariable, para examinar la correlación entre indicadores cruzados de fácil asociación lógico-significativa, por diarios, realizándose una comparativa entre ellos.

\section{Resultados}

\subsection{Análisis univariado (frecuencias generales)}

\subsubsection{Indicadores de cuantificación por tipo de imagen (1 a 7)}

Tal como aparece en la Tabla I del Anexo, el número total de fotografías computadas fue de 496, repartidas de la siguiente manera: 167 fotos de llamada a noticias, siendo la categoría mayoritaria, con el 33'6\% sobre el total de fotos computadas; 38 fotos de llamada a galerías (7'6\%) y 73 fotos referidas a otros contenidos informativos (14'7\%). Estos tres tipos suman las 278 fotografías informativas indicadas en el epígrafe anterior. Las fotos genéricas, consideradas no informativas, son 218. Trasladando estos valores a sus equivalencias porcentuales, se obtiene que en torno al $56 \%$ de las fotos computadas son informativas y el $44 \%$ restante no lo son.

El número total de frames registrados en el total de la muestra es de 91, cifra que si se suma al total de fotos da un resultado de 587. Tomado como referencia este valor numérico, indica que en términos respecto al global de la muestra existe una cifra cercana al $16 \%$ de frames respecto a un $84 \%$ de fotografías.

Dentro del recuento general se constata que la inserción de imágenes de carteles, fotogramas estáticos o "pantallazos" es un recurso empleado en las portadas de todos los ciberdiarios y en todas las ediciones examinadas.

\subsubsection{Indicadores de tamaño de la imagen (8 a 12)}

Para la consideración del tamaño de las fotos se ha tenido en cuenta como magnitud relevante el ancho de las mismas, estableciéndose en aras de la mayor concreción del estudio tres posibles rangos: ancho menor del 25\% del área de diseño, entre el 25\% y el 50\% y mayor del 50\%. Según el número de fotografías presentes en la página con cada uno de estos tamaños se estableció una escala que fija porcentualmente su cantidad sobre el total de fotos de cada página.

En función de todo ello, los resultados obtenidos (Tabla II del Anexo) indican que en 16 de las 20 portadas analizadas predomina de forma clara el empleo de fotos con tamaño menor al $25 \%$ del ancho de la mancha del diseño, lo cual afecta a más de la mitad de las fotos publicadas. Las fotografías en un tamaño entre el 25 y el 50\% del ancho disponible son siempre menos de la mitad, únicamente en tres páginas es mayor 
el número de fotos en este tamaño que el de las más pequeñas. Por último, sólo en dos páginas de las 20 examinadas se publica alguna fotografía de ancho mayor al 50\% de la mancha, y su número es mínimo: sólo una en ambos casos.

Para registrar la publicación de fotografías con ancho muy reducido, aproximadamente inferior al $10 \%$ del área de diseño, se introdujo el indicador 11 (efecto cromos). Este tipo de fotos ya está computado numéricamente en el indicador 8 (tamaño inferior al 25\%), por lo que vendría a dar cuenta de un grado extremo del mismo. Los resultados muestran que dicho efecto se da en 17 de las 20 portadas digitales analizadas (el $85 \%$ ), y concretamente de una forma muy acusada en 5 de ellas, es decir, que se trata de una praxis muy extendida en los diarios digitales.

A pesar del escaso tamaño de las fotos, como se aprecia en los valores obtenidos en el indicador 15, la tendencia muy mayoritaria es que los diarios digitales no permiten la descarga de las fotos a tamaño ampliado, entendiéndose por tal el que abarca al menos el ancho total del área de diseño. Esto sólo se da en 4 de las 20 portadas objeto de estudio (el $20 \%$ ).

\subsubsection{Indicadores de jerarquización visual (13 y 14)}

Este importante aspecto en la maquetación de los diarios de soporte papel se analiza en sus equivalentes on-line tomando como referencia dos indicadores: el número de tamaños distintos de fotografías y la existencia de una composición con una fotografía mayor que el resto. En tal sentido conviene recordar dos normas clásicas (González Díez y Pérez Cuadrado, 2001a: 147): "El interés gráfico se consigue mediante el empleo de fotos cortadas a tamaños diferentes. Se evita la monotonía”; y (González Díez y Pérez Cuadrado, 2001b: 147): "Debe darse siempre una foto que domine al resto. Para crear contraste de tamaño y ayudar a jerarquizar el mensaje.”

Los datos obtenidos en el primero de ellos, recogidos en la Tabla III del Anexo, indican que la tendencia mayoritaria es emplear entre 6 y 7 tamaños de fotografía diferentes, lo que se hace en 12 de las 20 portadas examinadas (el 60\%), mientras que un número de tamaños superior a 7 sólo se constata en 6 portadas (el $30 \%$ ). El número de tamaños entre 3 y 4 sólo se da en 2 portadas ( $10 \%$ de la muestra). Respecto al otro indicador considerado en este epígrafe, uso de composición con una foto mayor que las demás, únicamente se ha constatado en 3 páginas (el 15\%).

\subsubsection{Encuadres (indicador 15)}

Los resultados de este indicador aparecen en la Tabla III del Anexo y son bastante concluyentes, ya que se observa un muy notable predominio de las fotografías de encuadre corto (57\%), seguidas de las de plano 
medio (27\%), siendo muy escasas (16\%) las que ofrecen un plano general. En todas las portadas analizadas salvo en una las fotos de plano corto son mayoritarias, superando el 50\% del total en 18 de los 20 casos. Las fotos en plano general presentan unos porcentajes de utilización muy bajos, oscilando entre un máximo del 29 y un mínimo del 7\%, y las de plano medio poseen unos valores más altos, pero asimismo irregulares.

\subsubsection{Retratos (indicador 16)}

Aunque en el presente trabajo no se ha realizado un análisis de las fotografías por géneros, se incluye este indicador debido a la gran frecuencia de utilización de los retratos de personajes constatada en estudios precedentes. El criterio seguido para computar una foto como retrato quedó restringido a aquellas en las que claramente se aprecia una pose de los personajes. El retrato, en cuanto pose artificiosa, está muy próximo a los “clichés fotográficos, que es necesario evitar" (Jesús Zorrilla, 1997: 88).

Como dato más significativo de los resultados de este indicador (Tabla IV) se constata que en 9 de las 20 portadas analizadas (el $45 \%$ de la muestra) más de la mitad de las fotos son retratos, y que en otras 9 el porcentaje de retratos publicados oscila entre el 30 y el 49 por ciento.

\subsubsection{Valor informativo (indicador 17)}

Como se dijo en un epígrafe anterior, éste es el único indicador de tipo cualitativo incorporado al modelo de análisis. Su valor viene determinado por el cumplimiento de lo que se considera que son los cometidos fundamentales de la fotografía periodística: "la aportación de datos y la participación en la creación del sentido informativo del texto verboicónico" (Alonso Erusquin, 1995: 196), que se produce cuando la foto es la noticia en sí misma o aporta algún aspecto informativo relevante para su comprensión o interpretación.

El valor de este indicador se expresa en tanto por ciento respecto al total de fotos informativas de la página. El cómputo global obtenido en el análisis (Tabla IV del Anexo) cifra en torno al 15\% el grado de elocuencia informativa de las fotografías publicadas, lo cual implica que más del 85\% de las mismas carece de ella, o lo que es igual, aporta escasa o nula relevancia periodística a las noticias que ilustran.

\subsubsection{Pies de foto (indicador 18)}

El grado de empleo del pie de foto en las fotografías fue muy escaso (Tabla IV del Anexo), como muestra el hecho de que ninguna de las publicadas en 14 de las 20 ediciones consultadas llevaba pie, lo que equivale al 70\%. Únicamente en 6 páginas se utilizaba este recurso, pero siempre de una manera muy limitada, que sólo en una superó el 25\% de las fotos y sin sobrepasar nunca el $50 \%$. 


\subsubsection{Identificación de la autoría o fuente (indicador 19)}

Los índices generales de identificación del autor obtenidos son bastante bajos, como se aprecia en la Tabla IV del Anexo; sólo en una de las 20 portadas analizadas superó el 50\% de las fotografías, y apenas en dos de ellas osciló entre el 25 y el 50\%. En el extremo opuesto, se registraron 9 portadas en las que no se indicaba la autoría o fuente de ninguna foto, y 8 en las que la identificación se producía en menos del 25\% de estas imágenes.

\subsubsection{Tipos de Galerías accesibles desde portada (indicador 20)}

Se consideran cuatro valores posibles para este indicador, obviamente no excluyentes entre sí porque desde una misma página se puede acceder a diferentes tipos de galerías; éstas pueden ser: genéricas (por lo común denominadas “imágenes del día”), galerías específicas de secciones del diario, galerías de acontecimiento, referidas a un evento informativo concreto de especial interés o importancia, y galerías de lectores o participativas. Teniendo en cuenta sólo los valores globales del análisis, se verifica que en la totalidad de portadas se tiene acceso a galerías genéricas y de secciones, mientras que el vínculo a galerías de acontecimiento y de lectores se reduce al 50\% de los casos. Los resultados totales se recogen en la Tabla IV del Anexo.

\subsection{Análisis bivariable (comparativo)}

Los datos correspondientes a este epígrafe se recogen en la Tabla 2 del anexo.

\subsubsection{Tipos de imágenes por diarios}

En la Tabla I del Anexo figuran los resultados de este epígrafe. Se observa que sobre la cifra total de 496 fotografías, el diario con mayor número de ellas es Sur de Málaga, con 153, equivalentes al 30'8\% de la muestra. En orden decreciente le siguen La Vanguardia, con 121 fotos (24'3\% del total), La Voz de Galicia, que publicó 118 instantáneas (23’7\% del total) y en último lugar figura la edición digital del diario El Mundo, con 104 fotografías (20’9\%).

Por tipo de imagen y periódico, encontramos que El Mundo es el que mayor número de fotos de llamada a noticias (indicador 3) cuenta, con 55, equivalentes al 53\% de todas las publicadas por este mismo diario en las fechas analizadas. Respecto al valor global de la muestra en el mismo indicador, este porcentaje es aún más llamativo, pues sobrepasa a la media general en 20 puntos. La siguiente cabecera por número de fotos en esta misma categoría es La Voz de Galicia, siendo el 38'9\% de las incluidas en sus páginas y situándose más de 5 puntos por encima de la media general de la muestra. La Vanguardia aparece en tercer lugar, con unos porcentajes del 30’5\% respecto al total de fotos de las ediciones del mismo diario consultadas, y un des- 
cuadre negativo de 3 puntos en relación a la media general. Por último, Sur de Málaga presenta el valor más bajo en este indicador, con sólo un 17'6\% respecto al total de fotos del mismo diario, y 16 puntos por debajo de la media global.

Respecto a las fotos vinculadas a otros contenidos noticiosos (indicador 5), puede verse que su reparto por diarios es muy desigual. El Mundo registra nuevamente el valor más alto en referencia al número de fotografías del propio diario (el 34'6\%) como al de la muestra, cuya media sobrepasa holgadamente, en más de 16 puntos porcentuales. Le sigue La Voz de Galicia, en donde pertenecen a esta categoría el 18'6\% de todas las fotos publicadas, igualando prácticamente el valor medio. A gran distancia aparecen La Vanguardia y Sur, con valores muy alejados de los anteriores en las dos magnitudes medias consideradas.

El número de fotos de llamada a galerías (indicador 4) presenta unos porcentajes más homogéneos en los cuatro diarios, con desviaciones poco significativas respecto a la media general. En orden de mayor a menor peso cuantitativo se sitúan por este orden: La Vanguardia, Sur, El Mundo y La Voz de Galicia.

En lo referente a las fotos genéricas (indicador 6), donde más imágenes de este tipo se publican es Sur, tanto en cifras absolutas como en porcentajes relativos al mismo diario y al promedio de la muestra, superando éste en más de 26 puntos, y a gran distancia de las otras tres cabeceras examinadas. El número de ambos tipos de imágenes está igualado prácticamente al 50\% en La Vanguardia, y se decanta de forma rotunda en favor de las fotos informativas en El Mundo. Los ratios comparativos quedan de la siguiente manera:

El Mundo: 99 fotos de tipo informativo (el 95\%) y 6 genéricas (55\%).

La Voz de Galicia: 73 fotos informativas (62\%) y 45 genéricas 38\%).

La Vanguardia: 60 fotos informativas (49\%) y 61 (50\%) genéricas.

Sur: 47 fotos informativas (31\%) y 106 (69\%) genéricas.

El mayor índice de utilización de frames se da en las páginas de La Vanguardia, con 34 frente a 121 fotos, seguido por el diario Sur, que incluye el mismo número, si bien con un ratio proporcional menor, pues publica 153 fotos. En la muestra de El Mundo se computan 12 frames respecto a 104 fotografías y, por último, $\mathrm{LaVoz}$ de Galicia registra la menor utilización de este elemento, con 11 ocurrencias frente a 118 imágenes fotográficas. 


\subsubsection{Tamaño de imágenes por diarios}

La lectura por diarios de los indicadores 8 al 12 de la matriz aparece en la Tabla II del Apéndice y muestra una tendencia bastante homogénea, con sólo diferencias de matiz entre cada uno de ellos. Dentro de una tónica general que marca con claridad el predominio de las imágenes pequeñas, con un ancho menor del 25\% del área de composición, La Vanguardia es el periódico donde esta tendencia es más acusada, pues se da un claro abuso del llamado "efecto cromos" o miniaturización excesiva de las imágenes, que se aprecia en la totalidad de las páginas consultadas. En los otros tres ciberdiarios analizados las tendencias de composición de tamaño en las fotografías es bastante similar. Las únicas notas distintivas entre ellos son, por un lado, que sólo Sur de Málaga y La Voz de Galicia publican alguna fotografía de ancho superior al 50\% de la composición (aunque lo hacen de forma puntual) y, por otro, que salvo El Mundo ninguna otra cabecera da opción a descargar las fotos en tamaño grande.

\subsubsection{Jerarquización de imágenes por diarios}

Tal como figura en la Tabla III, de los cuatro periódicos digitales objeto de análisis, en tres de ellos (El Mundo, La Vanguardia y Sur) se aprecia que el empleo de fotos con diferente tamaño no sigue una pauta definida, sino que oscila de unas ediciones a otras, siendo más variable en Sur que en los otros dos. En La Vanguardia la tendencia a emplear mayor número de tamaños de fotos diferentes es más alta que en el resto. Por contra, la homogeneidad en este aspecto de la composición es total en La Voz de Galicia, pues en todas las ediciones consultadas el número de tamaños diferentes es siempre el mismo, lo cual quizás indica que en este periódico hay una pauta estilística concreta en dicho sentido.

Por lo que atañe a la otra técnica de jerarquización considerada en el análisis, la puesta en página de alguna fotografía a mayor tamaño que el resto, se emplea en tres de los cuatro diarios: El Mundo, Sur y La Voz de Galicia, pero sólo en el 25\% de las ediciones analizadas; en La Vanguardia no se ha constatado tal empleo.

\subsubsection{Encuadres por diarios}

Los valores obtenidos pueden consultarse en la Tabla III del Anexo, y son bastante similares en las cuatro cabeceras, si bien presentan por separado algunos rasgos diferenciadores. Así, El Mundo incluye mayor número de fotografías de encuadre general que el resto (el 19'6\% de las publicadas), lo que supone más de 3 puntos porcetuales por encima de la media (16\%) y alrededor de 4 puntos de diferencia respecto a los otros tres diarios. En fotografías de encuadre medio destaca numéricamente La Voz de Galicia, con un 38'6\%, lo que supera en más de 10 puntos a la media global, situada en el 27\%; El Mundo es el que presenta menor 
porcentaje de fotos con este encuadre, el 20 ' $4 \%$. En todos los diarios predomina claramente el plano corto (primer plano), siendo esta tendencia más acusada en Sur, con el 64'8\% de las fotos publicadas, lo que supone más de 7 puntos por encima de la media general (57\%); donde menos fotos de este tipo se publican es el La Voz de Galicia, el 46'4\%.

\subsubsection{Retratos por diarios}

Las fotografías de este género no sobrepasan el 50\% en ninguno de los diarios estudiados (Tabla IV del Anexo), pero se acercan mucho a esa cifra; el que más lo hace es $E l$ Mundo, con un 47\% de las mismas, seguido por Sur (46'8\%), La Vanguardia (43\%) y La Voz de Galicia (38’6\%). La media global está en el 43\%, lo que implica que todos los periódicos, salvo el último de los mencionados, igualan o superan ligeramente dicho porcentaje.

\subsubsection{Valor informativo por diarios}

Este indicador cualitativo, cuyos valores aparecen en la Tabla IV presenta muy escasas desigualdades entre unos periódicos y otros. La desviación máxima sobre la media (15’4\%) es de apenas cuatro puntos, y corresponde a Sur de Málaga (19’2\%), mientras que el valor mínimo lo marca La Voz de Galicia (10’6\%). Ligeramente por encima y por debajo de la media se encuentran, respectivamente, El Mundo (17'6\%) y La Vanguardia (14'2\%).

\subsubsection{Pies de foto por diarios}

A la luz de los datos de este indicador registrados en la Tabla IV, no se constata una tendencia uniforme en el empleo de este recurso, ni entre las diferentes ediciones de un mismo diario ni entre unas y otras cabeceras. La Voz de Galicia es el único caso donde no hay ninguna foto con pie, y en el resto siempre es un recurso minoritario, pues en ninguna página las fotos con pie sobrepasan el $25 \%$.

\subsubsection{Identificación de autoría por diarios}

En ninguno de los diarios analizados se identifica la autoría de la totalidad de las fotos publicadas en portada (Tabla IV), y sólo en una página de las 20 que integran la muestra el nivel de identificación superó el $50 \%$ de las publicadas ese día; fue precisamente en La Vanguardia, que es con diferencia donde se verifica una mayor tendencia a la identificación y donde, además, nunca se da el caso de que ninguna de las fotos publicadas aparezca sin este atributo. En el extremo opuesto se encuentra el diario Sur, pues en todos los casos la identificación es nula. El Mundo y La Voz de Galicia presentan un equilibro entre ambos extremos, pero dentro de unos niveles asimismo bajos. 


\subsubsection{Galerías accesibles por diarios}

Los resultados de este indicador plasmados en la Tabla IV muestran que el único diario que cuenta con acceso desde las portadas a los cuatro tipos de galerías considerados en el estudio es Sur. Tanto las ediciones digitales de El Mundo como La Vanguardia dan acceso en sus páginas de portada a tres tipos de galerías, ambos a las genéricas y las de secciones, y a ellas suma el diario madrileño las de acontecimiento, mientras que el barcelonés siempre presenta una llamada con vínculo a galerías de lectores. La Voz de Galicia es el más restrictivo en el empleo de este recurso, limitándose al vínculo con dos tipos de galerías: genéricas y de secciones.

\section{Conclusiones}

A partir de los resultados obtenidos, se pueden inferir las siguientes conclusiones:

1. Las portadas de los diarios digitales se caracterizan por una gran profusión iconográfica, claramente superior a sus homólogos de soporte papel. Teniendo en cuenta el poco espacio disponible en pantalla, ello produce una impresión un tanto masificada, abrumadora y dispersa.

2. La incorporación de fotogramas de vídeos congelados (frames) es cuantitativamente relevante y su uso es creciente en todos los diarios. Si a ello se une su posicionamiento semejante al de las fotografías más importantes, y su yuxtaposición con aquellas, al aparecer mezcladas ambas en las mismas áreas de la página, cobra fuerza su papel como elemento sustitutivo o suplantador de la fotografía.

3. Existe una tendencia muy marcada en los diarios digitales a publicar fotografías en tamaño muy reducido, que llega con frecuencia a la miniaturización. Este rasgo, unido a la masificación iconográfica y a una escasa jerarquización de las imágenes, contribuye a crear confusión visual en el lector y a que éste minusvalore aún más el sentido y la importancia de la fotografía periodística.

4. Por una lógica de causa-efecto, el pequeño tamaño en que se publican la mayoría de las fotos en los ciberdiarios actúa como condicionante fundamental respecto a los tipos de encuadre utilizados. Así, en todos los casos analizados predominan los primeros planos, ya que en las fotos de planos generales no se pueden apreciar los detalles. Esto implica que en gran parte de las imágenes no se tienen referencias situacionales ni escenográficas, sino sólo "caras" descontextualizadas de su marco. A ello se une la gran cantidad de fotosretrato de personajes en actitud de pose, lo cual supone una vuelta a la fotografía pre-periodística. La combinación de estos usos produce un claro empobrecimiento expresivo e informativo, así como una gran monotonía. 
5. La fotografía en los diarios digitales posee una relevancia informativa muy escasa, aporta muy poco valor añadido como elemento noticioso en sí mismo o como apoyo al núcleo del mensaje textual, y en su mayoría queda relegada a ser un componente simplemente decorativo. La fotografía deja de ser portadora de la noticia o de su clave esencial y en tal sentido el fotoperiodismo cede terreno claramente ante la foto-ilustración, lo cual de nuevo es un rasgo arcaizante.

6. Los pies de foto prácticamente desaparecen en los diarios digitales, en buena parte también como consecuencia del reducido tamaño con el que se maquetan, y también por el tratamiento mucho más ligero y sintético de los elementos textuales en los periódicos digitales.

7. Las galerías son las fórmulas emergentes del uso de la fotografía en los medios on-line. Se constata una progresiva diversificación de los tipos de galerías, con la incorporación de las de los lectores, y la posibilidad de acceder a las mismas directamente desde la portada. Por el lado positivo, esto abre nuevas posibilidades de enriquecimiento y especialización al fotoperiodismo, pero en medio del contexto masificado y confuso de la página, pierden gran parte de su vigor atractivo.

8. La mayor parte de las fotografías publicadas en los diarios digitales no lleva identificación de la autoría, lo cual puede ser indicativo de varios hechos relevantes, por ejemplo, que se trate casi siempre de fotos genéricas o de archivo o que no se haga uso de los fotógrafos de plantilla más que de forma muy puntual. Ambos son hechos muy significativos que abundan en la misma línea de otros precedentes: un retroceso claro con respecto a los diarios tradicionales.

9. Los periódicos analizados comparten en líneas generales las fórmulas de tratamiento de la fotografía apuntadas anteriormente. No hay grandes matices diferenciadores entre ellos y, en consecuencia, puede afirmarse que no tienen un estilo de diseño fotográfico propio, ni siquiera unas pautas de tratamiento de este elemento visual sistemáticas y evidentes para el lector. El diario que presenta una orientación ligeramente más periodística o informativa en el uso de la fotografía es El Mundo, pues publica un menor número de imágenes genéricas o decorativas que el resto, aun compartiendo en esencia con los demás el resto de tendencias. En sentido opuesto, el diario Sur muestra una mayor tendencia hacia el empleo más decorativo y superficial de la fotografía.

10. Como conclusión general, se confirman y en muchos aspectos se acentúan las principales tendencias en el tratamiento de la fotografía en los diarios digitales recogidas en los trabajos precedentes aquí referenciados. 


\section{Recomendaciones}

Tratándose de un tema aún poco explorado empíricamente, y dado el dinamismo de los medios periodísticos, fundamentalmente por la incorporación progresiva de nuevas herramientas tecnológicas, se propone para posteriores estudios varias líneas de trabajo: a) Ampliación del modelo de análisis propuesto en este artículo con nuevos indicadores y más especializados, por ejemplo referidos al análisis exhaustivo de las galerías, frames o a los factores de usabilidad de las fotografías. b) Realización de estudios referidos a ciberdiarios de países de nuestro ámbito geográfico o de otras zonas o continentes. c) Se estima que podría tener interés la realización de trabajos de tipo comparativo, para analizar el tratamiento de la fotografía periodística en diarios on-line y en soporte papel. D) Ampliación del campo de estudio a otros tipos de publicaciones informativas en red

\section{Referencias bibliográficas}

Alonso Erusquin, M. (1995): Fotoperiodismo: formas y código. Madrid: Síntesis.

Caminos Marcet, J.M.; Murillo, F; Armentia Vizuete, J. I. (2006): “El uso de la fotografía en los diarios digitales españoles", Comunicación y Sociedad, vol. XIX, num.2, pp. 9-38.

González Díez, L.; Pérez Cuadrado, P. (2001): Principios básicos del diseño periodístico. Madrid: Editorial Universitas.

Horton, S. (2006): "Universal Usability: A universal design approach to web usability". Disponible en: <http://universalusability.com/> [Consulta: 11 de enero de 2010]

Johnson, J. -The Bivings Group.(2008):”The use of Internet by America's largest newspapers.” Disponible en: <http://www.bivingsreport.com/2008/the-use-of-the-internet-by-americas-largest-newspapers-2008-edition/> [Consultado el: 20 de enero 2010].

Krug, S. (2001): No me hagas pensar: una aproximación a la usabilidad. Madrid: Pearson Educación.

Munhoz, P. (2007): “Estagios de desenvolvimento do fotojornalismo na Internet”, Diálogos \& Ciencia, Año V, n.11, pp. 1-15. Disponible en: <http://www.ftc.br/dialogos> [Consultado el: 19 de enero 2010].

Nielsen, J. (2000): Usabilidad. Diseño de sitios web. Madrid: Pearson Educación.

Rodríguez Merchán, E. (1993): La realidad fragmentada. Madrid: Universidad Complutense.

Sánchez Vigil, J.M., Marcos Recio, J.C., Villegas Tovar, R. (2007): “Los recursos fotográficos en los periódicos digitales. Valores de la fotografía digital". Ibersid 2007. pp. 211-218.

Villa, M. I. (2008): "Particularidades de la fotografía informativa en los medios online españoles". Revista Latina de Comunicación Social, pp. 303-312.

Zorrilla Ruiz, J. (1997): Introducción al diseño periodístico, Pamplona: Ediciones Universidad de Navarra.

$94\left|n^{\circ} 11\right|$ doxa.comunicación 
Anexos

Tabla I: Indicadores de cuantificación por tipo de imagen

\begin{tabular}{|c|c|c|c|c|c|c|c|}
\hline Periódico & Fecha & $\begin{array}{l}\text { Número } \\
\text { de fotos }\end{array}$ & $\begin{array}{l}\text { Número } \\
\text { de frames }\end{array}$ & $\begin{array}{c}\text { Fotos- } \\
\text { noticias }\end{array}$ & $\begin{array}{c}\text { Fotos- } \\
\text { galerías }\end{array}$ & $\begin{array}{l}\text { Otras fotos } \\
\text { infor. }\end{array}$ & $\begin{array}{c}\text { Fotos } \\
\text { genéricas (1) }\end{array}$ \\
\hline El Mundo & $19 / 01 / 2010$ & 23 & 2 & 9 & 2 & 11 & $1 \mathrm{~S}$ \\
\hline El Mundo & $20 / 01 / 2010$ & 23 & 1 & 13 & 1 & 8 & $1 \mathrm{~S}$ \\
\hline El Mundo & $21 / 01 / 2010$ & 18 & 2 & 10 & 1 & 6 & $1 \mathrm{~S}$ \\
\hline El Mundo & $22 / 01 / 2010$ & 18 & 4 & 10 & 1 & 6 & $2 \mathrm{~S}$ \\
\hline El Mundo & $25 / 01 / 2010$ & 22 & 3 & 15 & 1 & 5 & $1 \mathrm{~S}$ \\
\hline Totales parciales & & 104 & 12 & 57 & 6 & 36 & 6 \\
\hline La Vanguardia & 19/01/2010 & 28 & 7 & 10 & 4 & 2 & $7 \mathrm{P}, 5 \mathrm{~S}$ \\
\hline La Vanguardia & $20 / 01 / 2010$ & 26 & 6 & 9 & 4 & 1 & $7 \mathrm{P}, 5 \mathrm{~S}$ \\
\hline La Vanguardia & $21 / 01 / 2010$ & 23 & 7 & 6 & 4 & 1 & $7 \mathrm{P}, 5 \mathrm{~S}$ \\
\hline La Vanguardia & $22 / 01 / 2010$ & 21 & 7 & 5 & 3 & 1 & $7 \mathrm{P}, 5 \mathrm{~S}$ \\
\hline La Vanguardia & $25 / 01 / 2010$ & 23 & 7 & 7 & 2 & 1 & $8 \mathrm{P}, 5 \mathrm{~S}$ \\
\hline Totales parciales & & 121 & 34 & 37 & 17 & 6 & 61 \\
\hline Sur & 19/01/2010 & 31 & 7 & 7 & 2 & 2 & $10 \mathrm{~S}, 10 \mathrm{P}$ \\
\hline Sur & $20 / 01 / 2010$ & 32 & 8 & 8 & 2 & 2 & $10 \mathrm{~S}, 10 \mathrm{P}$ \\
\hline Sur & $21 / 01 / 2010$ & 27 & 6 & 2 & 3 & 2 & $10 \mathrm{~S}, 10 \mathrm{P}$ \\
\hline Sur & $22 / 01 / 2010$ & 33 & 6 & 6 & 2 & 2 & $12 \mathrm{~S}, 11 \mathrm{P}$ \\
\hline Sur & $25 / 01 / 2010$ & 30 & 7 & 4 & 2 & 1 & $12 \mathrm{~S}, 11 \mathrm{P}$ \\
\hline Totales parciales & & 153 & 34 & 27 & 11 & 9 & 106 \\
\hline Voz de Galicia & 19/01/2010 & 23 & 2 & 9 & 1 & 4 & $4 \mathrm{~S}, 5 \mathrm{P}$ \\
\hline Voz de Galicia & $20 / 01 / 2010$ & 23 & 1 & 9 & 1 & 4 & $3 S, 6 P$ \\
\hline Voz de Galicia & $21 / 01 / 2010$ & 23 & 1 & 7 & 1 & 6 & $3 S, 6 P$ \\
\hline Voz de Galicia & $22 / 01 / 2010$ & 25 & 3 & 10 & 1 & 5 & $3 S, 6 \mathrm{P}$ \\
\hline Voz de Galicia & $25 / 01 / 2010$ & 24 & 4 & 11 & 1 & 3 & $3 \mathrm{~S}, 6 \mathrm{P}$ \\
\hline
\end{tabular}




\begin{tabular}{|lcccccc|}
\hline Totales parciales & 118 & 11 & 46 & 5 & 22 & 45 \\
\hline TOTALES/PROMEDIOS & 496 & 91 & 167 & 38 & 73 & 218 \\
\hline
\end{tabular}

(1) $\mathrm{S}=$ Fotos genéricas de llamada a sección; $\mathrm{P}=$ fotos personales (avatares)

Tabla II: Indicadores de tamaño de la imagen

\begin{tabular}{|c|c|c|c|c|c|c|}
\hline Periódico & Fecha & $\begin{array}{l}\text { Tamaño } \\
<25 \%\end{array}$ & $\begin{array}{l}\text { Tamaño } \\
25-50 \%\end{array}$ & $\begin{array}{c}\text { Tamaño } \\
>50 \%\end{array}$ & $\begin{array}{l}\text { Efecto } \\
\text { cromos }\end{array}$ & $\begin{array}{c}\text { Descarga } \\
\text { tamaño grande }\end{array}$ \\
\hline El Mundo & $19 / 01 / 2010$ & 4 & 3 & 1 & No & 2 \\
\hline El Mundo & $20 / 01 / 2010$ & 4 & 3 & 1 & No & 2 \\
\hline El Mundo & $21 / 01 / 2010$ & 4 & 3 & 1 & No & 2 \\
\hline El Mundo & $22 / 01 / 2010$ & 4 & 3 & 1 & Sí & 2 \\
\hline El Mundo & $25 / 01 / 2010$ & 4 & 3 & 1 & Sí & 1 \\
\hline La Vanguardia & $19 / 01 / 2010$ & 4 & 2 & 1 & Sí-acusado & 1 \\
\hline La Vanguardia & $20 / 01 / 2010$ & 4 & 2 & 1 & Sí-acusado & 1 \\
\hline La Vanguardia & $21 / 01 / 2010$ & 4 & 2 & 1 & Sí-acusado & 1 \\
\hline La Vanguardia & $22 / 01 / 2010$ & 4 & 2 & 1 & Sí-acusado & 1 \\
\hline La Vanguardia & $25 / 01 / 2010$ & 4 & 2 & 1 & Sí-acusado & 1 \\
\hline Sur & $19 / 01 / 2010$ & 4 & 3 & 1 & Sí & 1 \\
\hline Sur & $20 / 01 / 2010$ & 4 & 3 & 2 & Sí & 1 \\
\hline Sur & $21 / 01 / 2010$ & 3 & 4 & 1 & Sí & 1 \\
\hline Sur & $22 / 01 / 2010$ & 3 & 4 & 1 & Sí & 1 \\
\hline Sur & $25 / 01 / 2010$ & 3 & 4 & 1 & Sí & 1 \\
\hline Voz de Galicia & $19 / 01 / 2010$ & 4 & 4 & 1 & Sí & 1 \\
\hline Voz de Galicia & $20 / 01 / 2010$ & 3 & 3 & 1 & Sí & 1 \\
\hline Voz de Galicia & $21 / 01 / 2010$ & 4 & 2 & 2 & Sí & 1 \\
\hline
\end{tabular}

96 | n $11 \mid$ doxa.comunicación 


\begin{tabular}{|lllllll|}
\hline Voz de Galicia & $22 / 01 / 2010$ & 4 & 3 & 1 & Sí & 1 \\
\hline Voz de Galicia & $25 / 01 / 2010$ & 4 & 3 & 1 & Sí & 1 \\
\hline
\end{tabular}

Tabla III: Indicadores de jerarquización visual y de encuadres

\begin{tabular}{|c|c|c|c|c|c|c|}
\hline Periódico & Fecha & $\begin{array}{l}\text { Tamaños } \\
\text { distintos }\end{array}$ & $\begin{array}{l}\text { Foto mayor } \\
\text { que el resto }\end{array}$ & $\begin{array}{c}\text { Encuadre: } \\
\text { general }\end{array}$ & $\begin{array}{l}\text { Encuadre: } \\
\text { medio }\end{array}$ & $\begin{array}{c}\text { Encuadre: } \\
\text { corto }\end{array}$ \\
\hline El Mundo & $19 / 01 / 2010$ & 4 & No & $14 \%$ & $10 \%$ & $76 \%$ \\
\hline El Mundo & $20 / 01 / 2010$ & 4 & No & $17 \%$ & $35 \%$ & $48 \%$ \\
\hline El Mundo & $21 / 01 / 2010$ & 4 & No & $19 \%$ & $25 \%$ & $56 \%$ \\
\hline El Mundo & $22 / 01 / 2010$ & 4 & No & $29 \%$ & $18 \%$ & $53 \%$ \\
\hline El Mundo & $25 / 01 / 2010$ & 4 & $\mathrm{Si}$ & $19 \%$ & $14 \%$ & $67 \%$ \\
\hline \multicolumn{7}{|c|}{ Totales parciales } \\
\hline La Vanguardia & $19 / 01 / 2010$ & 5 & No & $10 \%$ & $15 \%$ & $75 \%$ \\
\hline La Vanguardia & $20 / 01 / 2010$ & 5 & No & $23 \%$ & $20 \%$ & $57 \%$ \\
\hline La Vanguardia & $21 / 01 / 2010$ & 5 & No & $9 \%$ & $37 \%$ & $55 \%$ \\
\hline La Vanguardia & $22 / 01 / 2010$ & 5 & No & $22 \%$ & $22 \%$ & $56 \%$ \\
\hline La Vanguardia & $25 / 01 / 2010$ & 4 & No & $11 \%$ & $44 \%$ & $45 \%$ \\
\hline \multicolumn{7}{|c|}{ Totales parciales } \\
\hline Sur & $19 / 01 / 2010$ & 5 & No & $14 \%$ & $30 \%$ & $57 \%$ \\
\hline Sur & $20 / 01 / 2010$ & 3 & $\mathrm{Si}$ & $25 \%$ & $17 \%$ & $58 \%$ \\
\hline Sur & $21 / 01 / 2010$ & 3 & No & $14 \%$ & $14 \%$ & $72 \%$ \\
\hline Sur & $22 / 01 / 2010$ & 5 & No & $10 \%$ & $20 \%$ & $80 \%$ \\
\hline Sur & $25 / 01 / 2010$ & 4 & No & $14 \%$ & $29 \%$ & $57 \%$ \\
\hline \multicolumn{7}{|c|}{ Totales parciales } \\
\hline Voz de Galicia & $19 / 01 / 2010$ & 4 & No & $21 \%$ & $36 \%$ & $43 \%$ \\
\hline Voz de Galicia & $20 / 01 / 2010$ & 4 & No & $21 \%$ & $29 \%$ & $50 \%$ \\
\hline Voz de Galicia & $21 / 01 / 2010$ & 4 & $\mathrm{Si}$ & $7 \%$ & $57 \%$ & $36 \%$ \\
\hline
\end{tabular}




\begin{tabular}{|lllllll|}
\hline Voz de Galicia & $22 / 01 / 2010$ & 4 & No & $19 \%$ & $31 \%$ & $50 \%$ \\
\hline Voz de Galicia & $25 / 01 / 2010$ & 4 & No & $7 \%$ & $40 \%$ & $53 \%$ \\
\hline Totales parciales & & & & & \\
\hline TOTALES/PROMEDIOS
\end{tabular}

Tabla IV: Indicadores de múltiple naturaleza

\begin{tabular}{|c|c|c|c|c|c|c|}
\hline Periódico & Fecha & Retrato & $\begin{array}{c}\text { Fotos con valor } \\
\text { informativo }\end{array}$ & $\begin{array}{c}\text { Tiene pie } \\
\text { de foto }\end{array}$ & $\begin{array}{c}\text { Identificación } \\
\text { autoría }\end{array}$ & $\begin{array}{l}\text { Tipos de } \\
\text { galerías }\end{array}$ \\
\hline El Mundo & $19 / 01 / 2010$ & $52 \%$ & $14 \%$ & 2 & 2 & $1,2,3$ \\
\hline El Mundo & $20 / 01 / 2010$ & $62 \%$ & $47 \%$ & 1 & 1 & $1,2,3$ \\
\hline El Mundo & $21 / 01 / 2010$ & $31 \%$ & $6 \%$ & 1 & 2 & $1,2,3$ \\
\hline El Mundo & $22 / 01 / 2010$ & $35 \%$ & $12 \%$ & 2 & 2 & $1,2,3$ \\
\hline El Mundo & $25 / 01 / 2010$ & $57 \%$ & $9 \%$ & 1 & 1 & $1,2,3$ \\
\hline \multicolumn{7}{|l|}{ Totales parciales } \\
\hline & & & & & & $1,2,4$ \\
\hline La Vanguardia & $19 / 01 / 2010$ & $60 \%$ & $10 \%$ & 2 & 2 & $1,2,4$ \\
\hline La Vanguardia & $20 / 01 / 2010$ & $50 \%$ & $12 \%$ & 1 & 2 & $1,2,4$ \\
\hline La Vanguardia & $21 / 01 / 2010$ & $27 \%$ & $27 \%$ & 1 & 3 & $1,2,4$ \\
\hline La Vanguardia & $22 / 01 / 2010$ & $11 \%$ & $11 \%$ & 2 & 3 & $1,2,4$ \\
\hline La Vanguardia & $25 / 01 / 2010$ & $67 \%$ & $11 \%$ & 1 & 4 & $1,2,4$ \\
\hline \multicolumn{7}{|l|}{ Totales parciales } \\
\hline Sur & $19 / 01 / 2010$ & $52 \%$ & $10 \%$ & 3 & 1 & $1,2,3,4$ \\
\hline Sur & $20 / 01 / 2010$ & $42 \%$ & $28 \%$ & 1 & 1 & $1,2,3,4$ \\
\hline Sur & $21 / 01 / 2010$ & $43 \%$ & $14 \%$ & 1 & 1 & $1,2,3,4$ \\
\hline Sur & $22 / 01 / 2010$ & $40 \%$ & $30 \%$ & 2 & 1 & $1,2,3,4$ \\
\hline Sur & $25 / 01 / 2010$ & $57 \%$ & $14 \%$ & 1 & 1 & $1,2,3,4$ \\
\hline
\end{tabular}

$98\left|n^{\circ} 11\right|$ doxa.comunicación 


\begin{tabular}{|lllllll|}
\hline Voz de Galicia & $19 / 01 / 2010$ & $36 \%$ & $12 \%$ & 1 & 1 & 1,2 \\
\hline Voz de Galicia & $20 / 01 / 2010$ & $36 \%$ & $21 \%$ & 1 & 2 & 1,2 \\
\hline Voz de Galicia & $21 / 01 / 2010$ & $50 \%$ & $7 \%$ & 1 & 2 & 1,2 \\
\hline Voz de Galicia & $22 / 01 / 2010$ & $31 \%$ & $6 \%$ & 1 & 1 & 1,2 \\
\hline Voz de Galicia & $25 / 01 / 2010$ & $40 \%$ & $7 \%$ & 1 & 2 & 1,2 \\
\hline Totales parciales & & & $\mathbf{1 5} \mathbf{4} \%$ & & \\
\hline TOTALES/PROMEDIOS & &
\end{tabular}


